\title{
Extrapleural locating method in computed tomography-guided needle biopsies of 1,106 lung lesions
}

\author{
YUE-HUA WEI $^{*}$, FU-XIANG ZHOU ${ }^{1,2^{*}}$, YAN LI $^{2,3}$, YUN-FENG ZHOU $^{1,2}$, \\ KRISHNA ANISH ${ }^{4}$, LI-YING XU ${ }^{4}$ and MEI-YAN LIAO ${ }^{2,4}$ \\ ${ }^{1}$ Department of Radiation and Medical Oncology; ${ }^{2}$ Hubei Key Laboratory of Tumor Biological Behaviors, \\ Hubei Cancer Clinical Study Center; ${ }^{3}$ Department of Oncology; ${ }^{4}$ Department of Radiology, \\ Zhongnan Hospital of Wuhan University, Wuhan, Hubei 430071, P.R. China
}

Received February 24, 2015; Accepted July 24, 2015

DOI: $10.3892 /$ etm.2015.2735

\begin{abstract}
Transthoracic needle biopsy is considered to be safe and effective for the diagnosis of focal lung lesions. The aim of the present study was to evaluate factors affecting the accuracy and safety of automated cutting needle lung biopsy (ACNB) using a new extrapleural locating (EPL) method. Computed tomography (CT)-guided needle biopsies were performed on 1,065 patients between March 2005 and May 2012 using the EPL method. The locating needle remained in the chest following extrapleural positioning, while the radiologist confirmed the puncture angle and distance between the locating needle and lesion. The biopsy instrument was advanced into the lung, and the core needle was subsequently fired into the lesion based on the direction indicated by the locating needle. Univariate and multivariate regression analyses were used to evaluate the diagnostic accuracy and safety of the procedure. The sensitivity, specificity, positive predictive value and negative predictive value of the extrapleural method were $91.9,100,100$ and $82.9 \%$, respectively, and the overall diagnostic accuracy was $94.2 \%$. Significant risk factors affecting accuracy were younger age, atelectasis, hemoptysis and lesion depth $(\mathrm{P}<0.03)$. Multivariate logistic regression analysis revealed that the risk of malignant lesions receiving a false-negative diagnosis decreased for each additional year of subject age [odds ratio (OR), 0.97; $\mathrm{P}=0.027$ ] and increased with each millimeter increase in lesion depth $(\mathrm{OR}, 1.03 ; \mathrm{P}=0.008)$.
\end{abstract}

Correspondence to: Dr Mei-Yan Liao, Department of Radiology, Zhongnan Hospital of Wuhan University, 169 Donghu Road, Wuhan, Hubei 430071, P.R. China

E-mail: liaomeiyan@aliyun.com

*Contributed equally

Abbreviations: ACNB, automated cutting needle lung biopsy; EPL, extrapleural locating; CT, computed tomography; OR, odds ratio; ED, effective dose; DLP, dose-length product

Key words: computed tomography scan, biopsy, atelectasis, hemoptysis, pneumothorax
Among the 1,106 lesions biopsied, 207 were associated with pneumothorax, 251 with hemorrhage and 58 with hemoptysis. Multivariate analysis revealed that lesion size and emphysema affected pneumothorax incidence, while age, lesion location and depth and emphysema significantly affected hemorrhage incidence $(\mathrm{P}<0.05)$. In conclusion, low-dose, CT-guided ACNB with the EPL method provides a safe and accurate diagnosis.

\section{Introduction}

Computed tomography (CT)-guided transthoracic needle biopsy is a well-established, effective and safe technique for the diagnosis of focal lung lesions $(1,2)$ and has exhibited high diagnostic accuracy and specificity (3). No differences have been detected between single-needle transthoracic needle biopsy and a coaxial technique with regard to diagnostic accuracy (4). Conventional CT-guided transthoracic needle biopsy, however, is a method for locating lesion-edges that increases the dwell time of the needle within the lung while scanning prior to biopsy $(3,5-8)$. The reported dwell times during conventional CT range between 29 and 41 min $(4,6,9,10)$. Longer dwell times are believed to result in greater needle motion during respiration, leading to the widening of the pleural puncture site $(2,11-13)$. Pneumothorax and hemorrhage are the most frequent complications associated with the procedure (11,14-17). Other potential factors affecting the rate of complications include lesion depth and size, presence of atelectasis and patient age (13-16,18-22).

In order to reduce the needle dwell time in the lungs and reduce complications, we have established an extrapleural locating (EPL) method that maintains the needle tip outside the visceral pleura prior to biopsy. Our previous pilot studies have involved only small sample sizes $(23,24)$; however, the preliminary results of these studies indicated that the EPL method was accurate and safe, and decreased the dwell time compared with conventional techniques $(4,6,9,10)$. Furthermore, EPL was shown to improve the false-negative rate $(23,24)$. Factors that affected accuracy included lesion depth and size, necrosis and the number of pleural passes $(9,22,25,26)$.

The aim of the present study was to assess the efficacy of the low-dose, CT-guided EPL method and extrapleural percutaneous lung biopsy on a larger cohort of patients. We 
hypothesized that this novel technique would reduce complications during low-dose, CT-guided automated cutting needle biopsy (ACNB), compared with results from previously published studies. Thus, a range of factors affecting accuracy and safety were evaluated during ACNB using a new EPL method.

\section{Subjects and methods}

Subjects. The Ethics Committee of the Zhongnan Hospital of Wuhan University (Wuhan, China) approved the study protocol and provided permission to perform this study. Each patient provided signed informed consent prior to participation.

This study was a retrospective analysis of 1,106 percutaneous CT-guided ACNBs with EPL performed on 1,065 patients between March 2005 and May 2012. All procedures were performed by the two radiologists that were experienced in performing CT-guided lung biopsies. Percutaneous CT-guided ACNB with an EPL technique was indicated in any patient with a lung lesion requiring biopsy. Patients with pleural-based tumors, such as mesothelioma, or pleural-based metastases were excluded, as this study reported only the results of percutaneous lung biopsy.

EPL method. A CT scan of the chest using a conventional CT Scanner (Somatom Sensation 16; Siemens Healthcare, Forchheim, Germany) was initially performed to identify the lesion (Fig. 1A). Prior to the biopsy, patients with deep intraparenchymal lesions or lesions adjacent to blood vessels received 1 KU hemocoagulase (H20041730; Jinzhou Ahon Pharmaceuticals Co., Ltd., Jinzhou, China) intramuscularly, as previously described (27).

Prior to the procedure, the radiologist described the biopsy process to the patient and positioned the patient in supine, prone or lateral positions to minimize puncture depth, and to avoid contact with bone and large blood vessels. After placing the patient in the scanner, the patient was trained in the breath-holding technique to ensure they were able to maintain the required magnitude of breath-hold during the CT scans and biopsy.

An initial localization scan with a low-dose technique (Lung CARE Series, Siemens Sensation 16 CT scan: 20-50 mA; $120 \mathrm{kV}$; scan field, 30-60 mm) through the region of interest was performed at a slice thickness of $5 \mathrm{~mm}$ and viewed on lung and soft-tissue windows. Localization was performed following a review of conventional CT images and by using laser positioning and metal skin markers (Biopsy single series: $50 \mathrm{~mA} ; 120 \mathrm{kV} ; 10$-mm thickness) to indicate the site of needle entry and direction of approach for biopsy. During the procedure, the ribs, lung bullae, vessels, fissures and low-density areas were avoided and the amount of aerated lung tissue traversed was minimized.

After ensuring that the direction of needle approach was perpendicular to the chest wall, the thickness of the thoracic wall was measured from the skin marker to the pleural surface (Fig. 1B) to determine the depth of anesthesia required and the depth of needle insertion. Using an aseptic technique with a 23 -gauge needle, local anesthetic (lidocaine $1 \%$ ) was administered. The anesthetic needle was inserted into the chest wall pleura as the locating needle. In patients with a thin chest wall, in which the anesthetic needle was unable to be fixed automatically, the operator directly applied a biopsy needle (Bard ${ }^{\circledR}$ Max-Core ${ }^{\circledR}$ Core Needle Biopsy Instrument; Bard Biopsy Systems, Tempe, AZ, USA) for positioning. Once the core gun had been inserted into the chest wall, the radiology assistant, wearing X-ray protective gear, fixed the core gun manually and the low-dose CT scan, with a dose-length product (DLP) of $6 \mathrm{mGy} / \mathrm{cm}$, was performed for EPL positioning (Fig. 1C). The radiologist confirmed the puncture angle and distances between the locating pin and lesion based on the CT data. The position of the lesion in relation to the tip of the locating needle, the precise distance to the margin of the lesion and the needle-pleura angle (defined as the angle between the locating needle and the line vertical to pleural surface) (Fig. 1D and E) were optimized using sequential CT scanning (Biopsy single series: $50 \mathrm{~mA} ; 120 \mathrm{kV}$; scan field, $13.5 \mathrm{~mm})$.

According to the data obtained from the repeat CT scan, the trajectory of the locating needle was adjusted under the chest wall pleura. The Bard Max-Core Core Needle was directly advanced into the lung and fired to obtain a core of tissue (typically 2-cm in length) from the lesion, based on data including direction, angle and depth obtained using the locating needle, following which the needle gun was withdrawn. The needle dwell time within the lung was measured, as the time between the biopsy needle puncturing the lung and its withdrawal from the lungs by the radiologist. The extracted tissue was examined by the naked eye. If soft tissue was evident in the sample, the biopsy was considered successful and the specimens obtained were placed in formalin solution using a saline-filled syringe. In general, to ensure that the tissue block was sufficient for histological examination, the biopsy was repeated 2-3 times, with slight adjustment of the transthoracic puncture angle and depth used. If pneumothorax occurred and caused the lesion to shift, or if adequate tissue was not obtained during the procedure, a repeat localization CT scan with EPL was performed. In order to avoid air embolism, the procedure was terminated if the patient coughed or hemoptysis ensued. Following completion of the biopsy, the biopsy area was scanned using conventional CT guidance (Biopsy single series: $50 \mathrm{~mA} ; 120 \mathrm{kV}$; thickness, $4.5 \mathrm{~mm}$; scan field, $13.5 \mathrm{~mm}$ ) to exclude pneumothorax or hemorrhage (Fig. 1F). The biopsy gun should advance to the depth displayed in Fig. 2.

Final diagnosis. The final diagnosis for each patient was based on the results of the surgery, response to relevant therapy, or clinical observations at month 24 of clinical follow-up. The biopsy specimens were evaluated by an experienced pathologist and the final diagnosis was confirmed by surgery. Histological findings obtained by biopsy were compatible with the patient's clinical disease manifestations. Atypical adenomatous hyperplasia was defined as malignancy in this series, as previously described (28).

Data collection. Data collected included details regarding patient information (gender, age), nature of the lesion (location, type, depth, size, presence of emphysema, contrast enhancement) and the presence of atelectactic lung tissue 
A

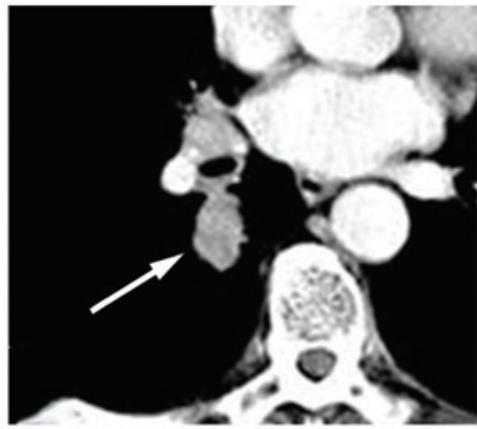

D

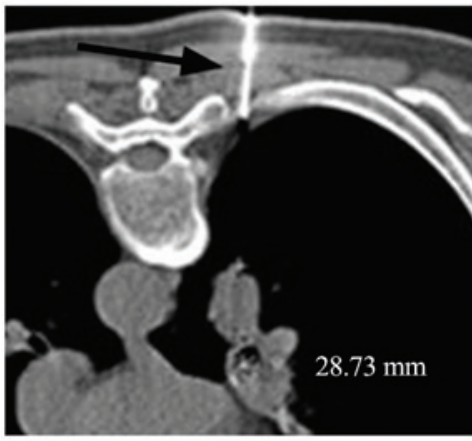

B

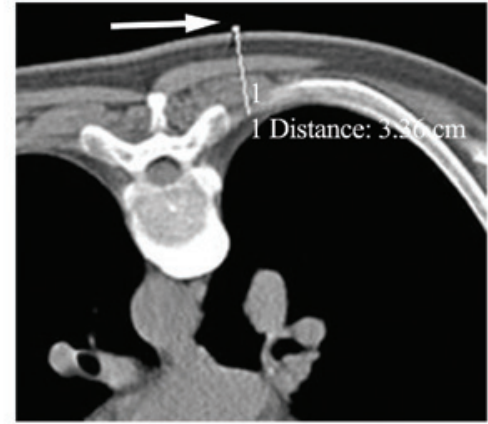

$\mathbf{E}$

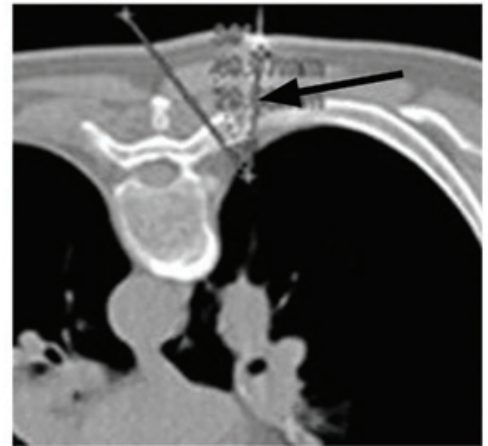

C

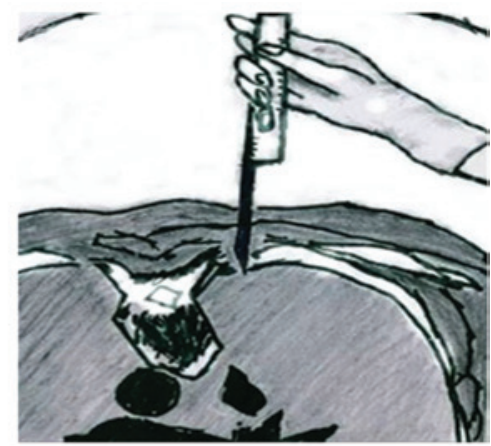

F

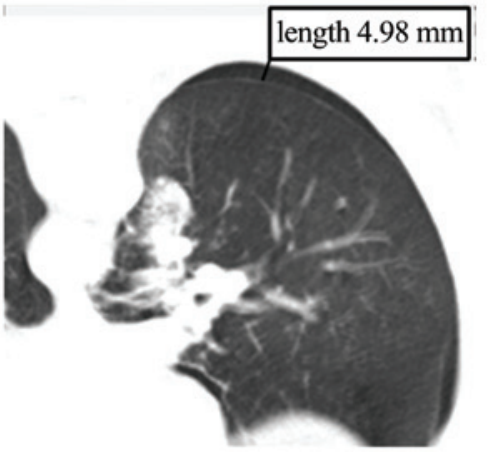

Figure 1. A 67-year-old man with a single, solid pulmonary nodule underwent automated cutting needle lung biopsy with extrapleural locating. (A) Pre-operative CT scan with enhancement demonstrating a nodule in the right lower lobe (arrow). (B) The patient was placed in the prone position. Axial CT imaging showed a skin marker (arrow) indicating the most favorable needle entry point; the thoracic wall thickness was $3.36 \mathrm{~cm}$. (C) A core gun had been inserted into the chest wall outside the pleural area, the radiology assistant, wearing X-ray protective gear, fixed the core gun manually and performed the low-dose CT scan. (D) Introduction of the biopsy needle (arrow) into the soft tissues up to the pleural surface; the lesion depth from the needle tip to the lesion margin was $28.73 \mathrm{~mm}$. (E) The needle-pleural angle was defined as the intersection angle between biopsy needle and the line which vertical to pleural, which is $34^{\circ}$ ( arrow). (F) Axial CT image acquired immediately after biopsy demonstrating the onset of pneumothorax. CT, computed tomography.

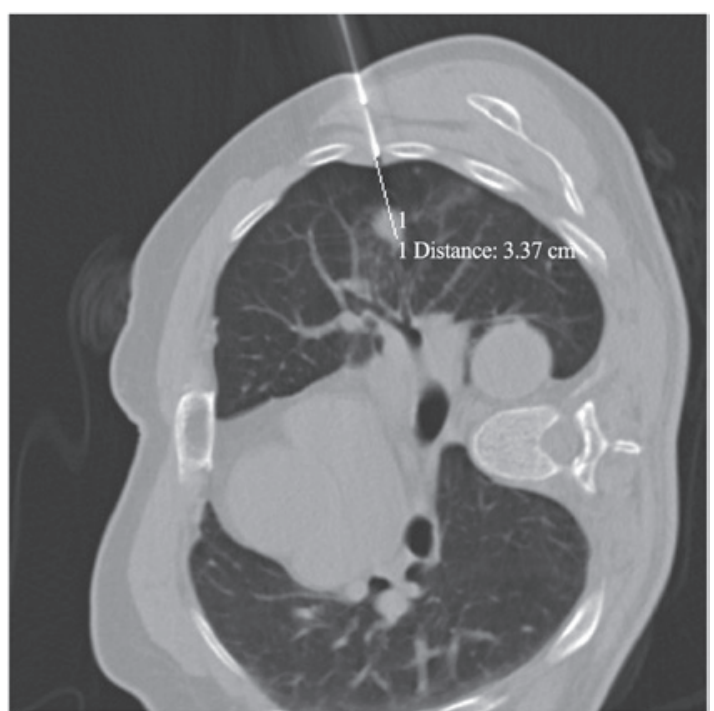

Figure 2. A 55-year-old man with adenocarcinoma, diagnosed using automated cutting needle lung biopsy with EPL. The upper left lung lesion size measured $12 \mathrm{~mm}$. During pre-positioning for EPL biopsy, the distance between the biopsy gunpoint and the proximal edge of the lesion measured $34 \mathrm{~mm}$. The gun was known to advance $22 \mathrm{~mm}$ due to the trigger of the biopsy gun; thus, the radiologist aimed to use the biopsy gun to enter the lung to a depth of $12 \mathrm{~mm}$. EPL, extrapleural locating.

adjacent to the lesion, which could increase the difficulty of distinguishing between healthy and tumor tissue. In addition, details of the procedure (position, needle size, number of EPL attempts, needle-pleura angle), complications (pneumothorax, hemorrhage, hemoptysis) and the histological results (benign versus malignant) were collected.

Potential complications of the EPL method included the presence of an immediate pneumothorax or hemorrhage on the post-biopsy CT images, the presence of a pneumothorax on the chest radiograph at $4 \mathrm{~h}$ post-biopsy and hemoptysis. Hemorrhage was also graded using the following criteria: i) Mild, hemorrhage presenting as haziness along the needle tracks or in adjacent air spaces on the CT scan; ii) moderate, occurrence of fewer than five episodes of hemoptysis estimated at $<30 \mathrm{ml}$ blood or minimal hemothorax; and iii) severe, hemoptysis or hemothorax associated with hemodynamic instability (13).

The presence of pneumothorax was assessed by a low-dose CT technique immediately subsequent to biopsy while the patient was on the CT scan table. Pneumothorax was graded using the following criteria: i) Mild, lung surface retraction of $\leq 2 \mathrm{~cm}$; ii) moderate, lung surface retraction of between 2 and $4 \mathrm{~cm}$; and iii) severe, lung surface retraction of $\geq 4 \mathrm{~cm}$ (13). Patients that were clinically stable remained under medical observation for $12 \mathrm{~h}$ prior to discharge (29). A chest radiograph was performed for all patients at $4 \mathrm{~h}$ after the procedure or sooner if they exhibited symptoms before this time.

Lesion size was measured along the needle path maximum long-axis diameter on the mediastinal windows. Lesion depth was measured from the point of pleural puncture to the nearest edge of the lung lesion along the needle path. Lesion type was divided into central versus peripheral. The definitions of 

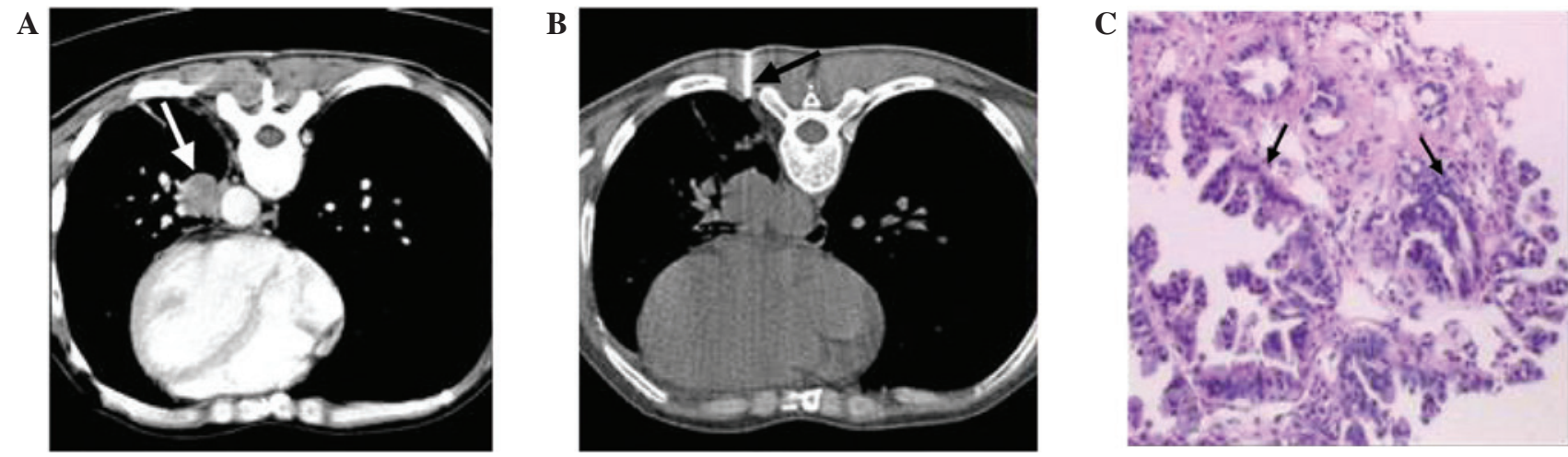

Figure 3. A 45-year-old man with well-differentiated adenocarcinoma, diagnosed using automated cutting needle lung biopsy with EPL. (A) An initial scan obtained prior to the biopsy showed a central lesion in the left lower lobe (white arrow). (B) Computed tomography scan obtained following the biopsy showed the needle point positioned outside the pleural surface (using the EPL method) to obtain the minimal distance from the nodule (black arrow). (C) High-power view of the nodule showed neoplastic gland formation (black arrows) (hematoxylin and eosin stain; magnification, x100). EPL, extrapleural locating.

central and peripheral lesions were based on imaging observation. Lesions that originated in the segmental bronchi or above bronchial lesions were graded as central lesions (Fig. 3), whereas lesions that originated in the lower bronchi were graded as peripheral lesions.

Emphysema was defined as $\leq 900 \mathrm{HU}$, in which $\leq 900 \mathrm{HU}$ was used as the threshold for determining emphysema (30). The emphysema status was classified as follows: Group 1, no emphysemic tissue surrounding the lesion; group 2, emphysemic tissue surrounding the lesion, but distant from the needle tract; and group 3, prominent emphysemic tissue in the needle tract.

The Somatom Sensation 16 CT biopsy scanner was able to record the radiation dose administered throughout the entire scanning process. Total effective dose (ED) for all procedures was obtained directly from the CT station. Theoretically, $\mathrm{ED}(\mathrm{mSv})=\operatorname{DLP} \mathrm{x} \mathrm{k}$, where $\mathrm{k}=0.014(\mathrm{mSv} / \mathrm{mGy} / \mathrm{cm})(31)$. Procedural duration was defined as the time between the first and last CT slice performed during the procedure.

Statistical analysis. Distributions of quantitative data were compared using the Student's t-test or the Mann-Whitney U-test, for analyzing the factors with or without a normal distribution, respectively. Distribution of qualitative data was compared using a $\chi^{2}$ test or a bilateral Fisher's exact test. Categorical variables are presented as counts and percentages, with $\chi^{2}$ tests for group comparisons. Logistic regression models were performed to detect the risk factors for diagnostic accuracy and complications. Continuous variables were stratified into groups for logistic regression analyses of complications. Using a forward procedure, only variables considered to be significant on univariate analysis $(\mathrm{P}<0.05)$ were subsequently introduced to multivariate logistic regression modeling to assess their contribution to diagnostic accuracy and the risk of pneumothorax, hemorrhage and hemoptysis. A two-sided $\mathrm{P}<0.05$ was considered to indicate a statistically significant difference. SAS statistics software, version 9.2 (SAS Institute Inc., Cary, NC, USA) was used for all analyses.

\section{Results}

General data. A total of 1,106 percutaneous ACNBs were performed in 1,065 patients (733 men and 332 women) with a mean age of $59 \pm 12$ years, including 290 outpatients and 775 inpatients. Among these, 198 cases underwent the procedure using a biopsy needle as a locating needle for EPL. The patients were primarily inpatients requiring pathological evaluation of their lesions. Among the 1,106 biopsies performed, 794 lesions were malignant and 312 were benign (Table I).

The overall diagnostic accuracy was $94.2 \%$. A specific diagnosis was achieved in $81.4 \%$ of the benign and $84.5 \%$ of the malignant lesions (Table I). The overall specific diagnostic rate was $83.6 \%$.

Risk factors affecting accuracy. The risk factors affecting accuracy are presented in Table II. Results of the univariate logistic regression analysis indicated that younger age, lesion type and depth, atelectasis and hemoptysis significantly affected accuracy $(\mathrm{P}<0.05$; Table II). Factors that were significant on the univariate analyses were included in the multivariate model.

Results of the multivariate analysis suggested that the significant risk factors affecting accuracy included younger age, atelectasis, hemoptysis and lesion depth $(\mathrm{P}<0.03$; Table II). In the 794 cases of malignant lesions, there were 64 false-negative results, including 15 false-negative cases in patients $\leq 50$ years old $(15 / 113,13.27 \%), 19$ false-negative cases in patients 51-60 years old (19/238,8.00\%), 22 false-negative cases in patients $61-70$ years old $(22 / 264,8.33 \%)$ and 8 false-negative cases in patients aged $>70$ years $(8 / 179$, $4.47 \%$ ). Among the 64 cases of malignant lesions, atelectasis was present in 24 cases $(24 / 93,25.81 \%)$, while there were 40 false-negative cases with no atelectasis (40/701, 5.71\%); hemoptysis appeared in 10 cases $(10 / 38,26.32 \%)$, while there was no hemoptysis in 54 cases $(54 / 756,7.14 \%)$. Combining the malignant and benign lesions, hemorrhage occurred in 28 subjects $(28 / 251,11.16 \%)$ that had been administered hemocoagulase and 5 of the 58 subjects $(8.62 \%)$ with hemoptysis had received hemocoagulase.

Lesion size had no effect on the false-negative results. Among the 64 false-negative cases, there were 17 cases with a lesion size measuring $\leq 20 \mathrm{~mm}, 11$ measuring $21-30 \mathrm{~mm}$, 9 measuring $31-40 \mathrm{~mm}, 12$ measuring $41-50 \mathrm{~mm}$ and 15 measuring 51-88 $\mathrm{mm}$. 
Table I. Characteristics of malignant $(n=794)$ and benign $(n=312)$ lesions.

\begin{tabular}{|c|c|c|c|c|}
\hline Characteristic & Total, n (\%) & Malignant, n (\%) & Benign, n (\%) & P-value \\
\hline Gender & & & & $0.017^{\mathrm{a}}$ \\
\hline Male & $757(68.44)$ & $560(70.53)$ & $197(63.14)$ & \\
\hline Female & $349(31.56)$ & $234(29.47)$ & 115 (36.86) & \\
\hline Age, years & & & & $<0.001^{\mathrm{a}}$ \\
\hline$\leq 50$ & $236(21.34)$ & $113(14.23)$ & $123(39.42)$ & \\
\hline $51-60$ & $331(29.93)$ & $238(29.97)$ & $93(29.81)$ & \\
\hline $61-70$ & $330(29.84)$ & $264(33.25)$ & $66(21.15)$ & \\
\hline$>70$ & $209(18.9)$ & $179(22.54)$ & $30(9.62)$ & \\
\hline Lesion location, lobe & & & & $0.012^{\mathrm{a}}$ \\
\hline Right upper & $333(30.11)$ & $251(31.61)$ & $82(26.28)$ & \\
\hline Right middle & $46(4.16)$ & $24(3.02)$ & $22(7.05)$ & \\
\hline Right lower & $242(21.88)$ & $169(21.28)$ & $73(23.4)$ & \\
\hline Left upper & $273(24.68)$ & $203(25.57)$ & $70(22.44)$ & \\
\hline Left lower & $212(19.17)$ & $147(18.51)$ & $65(20.83)$ & \\
\hline Lesion type & & & & $<0.001^{\mathrm{a}}$ \\
\hline Central & $265(23.96)$ & $247(31.11)$ & $18(5.77)$ & \\
\hline Peripheral & $841(76.04)$ & $547(68.89)$ & $294(94.23)$ & \\
\hline Lesion depth, mm & & & & $<0.001^{\mathrm{a}}$ \\
\hline 0 & $521(47.11)$ & $348(43.83)$ & $173(55.45)$ & \\
\hline $1-10$ & $195(17.63)$ & $117(14.74)$ & $78(25)$ & \\
\hline $11-20$ & $216(19.53)$ & $175(22.04)$ & $41(13.14)$ & \\
\hline $21-30$ & $108(9.76)$ & $94(11.84)$ & $14(4.49)$ & \\
\hline$>30$ & $66(5.97)$ & $60(7.56)$ & $6(1.92)$ & \\
\hline Lesion size, $\mathrm{mm}$ & & & & $<0.001^{\mathrm{a}}$ \\
\hline$\leq 10$ & $57(5.15)$ & $22(2.77)$ & $35(11.22)$ & \\
\hline $11-20$ & $213(19.26)$ & $132(16.62)$ & $81(25.96)$ & \\
\hline $21-30$ & $273(24.68)$ & $171(21.54)$ & $102(32.69)$ & \\
\hline $31-40$ & $227(20.52)$ & $174(21.91)$ & $53(16.99)$ & \\
\hline$>40$ & $336(30.38)$ & $295(37.15)$ & $41(13.14)$ & \\
\hline Emphysema & & & & 0.063 \\
\hline $0^{\mathrm{b}}$ & $423(38.25)$ & $287(36.15)$ & $136(43.59)$ & \\
\hline $1^{\mathrm{c}}$ & $450(40.69)$ & $337(42.44)$ & $113(36.22)$ & \\
\hline $2^{\mathrm{d}}$ & $233(21.07)$ & $170(21.41)$ & 63 (20.19) & \\
\hline Contrast enhancement & & & & 0.087 \\
\hline Yes & $336(30.38)$ & $253(31.86)$ & $83(26.60)$ & \\
\hline No & $770(69.62)$ & $541(68.14)$ & $229(73.40)$ & \\
\hline Atelectasis & & & & $0.005^{\mathrm{a}}$ \\
\hline Yes & $112(10.13)$ & $93(11.71)$ & $19(6.09)$ & \\
\hline No & $994(89.87)$ & $701(88.29)$ & $293(93.91)$ & \\
\hline Position & & & & 0.665 \\
\hline Lateral & $240(21.7)$ & $176(22.17)$ & $64(20.51)$ & \\
\hline Prone & $586(52.98)$ & $414(52.14)$ & $172(55.13)$ & \\
\hline Supine & $280(25.32)$ & $204(25.69)$ & $76(24.36)$ & \\
\hline Needle size, $\mathrm{G}$ & & & & $0.008^{\mathrm{a}}$ \\
\hline 16 & $105(9.49)$ & $87(10.96)$ & $18(5.77)$ & \\
\hline 18 & $1,001(90.51)$ & $707(89.04)$ & $294(94.23)$ & \\
\hline Number of attempts & & & & $0.034^{\mathrm{a}}$ \\
\hline$\leq 2$ & $396(35.8)$ & $277(34.89)$ & 119 (38.14) & \\
\hline 3 & $581(52.53)$ & $412(51.89)$ & $169(54.17)$ & \\
\hline$\geq 4$ & $129(11.66)$ & $105(13.22)$ & $24(7.69)$ & \\
\hline
\end{tabular}


Table I. Continued.

\begin{tabular}{|c|c|c|c|c|}
\hline Characteristic & Total, n (\%) & Malignant, n (\%) & Benign, n (\%) & P-value \\
\hline Needle-pleura angle, degrees & & & & 0.071 \\
\hline$\leq 15$ & $923(83.45)$ & $672(84.63)$ & $251(80.45)$ & \\
\hline $16-30$ & $110(9.95)$ & $78(9.82)$ & $32(10.26)$ & \\
\hline$>30$ & $73(6.60)$ & $44(5.54)$ & $29(9.29)$ & \\
\hline Pneumothorax & & & & 0.783 \\
\hline Yes & $207(18.72)$ & $147(18.51)$ & $60(19.23)$ & \\
\hline No & $899(81.28)$ & $647(81.49)$ & $252(80.77)$ & \\
\hline Hemorrhage & & & & $0.003^{\mathrm{a}}$ \\
\hline Yes & $251(22.69)$ & $199(25.06)$ & $52(16.67)$ & \\
\hline No & $855(77.31)$ & $595(74.94)$ & $260(83.33)$ & \\
\hline Hemoptysis & & & & 0.276 \\
\hline Yes & $58(5.24)$ & $38(4.79)$ & $20(6.41)$ & \\
\hline No & $1,048(94.76)$ & $756(95.21)$ & $292(93.59)$ & \\
\hline Diagnosis & & & & $<0.001^{\mathrm{a}}$ \\
\hline Positive & $730(66.00)$ & $730(91.94)$ & $0(0.00)$ & \\
\hline Negative & $376(34.00)$ & $64(8.06)$ & $312(100.00)$ & \\
\hline Specific diagnosis & & & & 0.245 \\
\hline Yes & $925(83.63)$ & $671(84.51)$ & $254(81.41)$ & \\
\hline No & $181(16.37)$ & $123(15.49)$ & $58(18.59)$ & \\
\hline \multicolumn{5}{|l|}{ False negative } \\
\hline Yes & $64(8.06)$ & $64(8.06)$ & & \\
\hline No & 730 (91.94) & 730 (91.94) & & \\
\hline
\end{tabular}

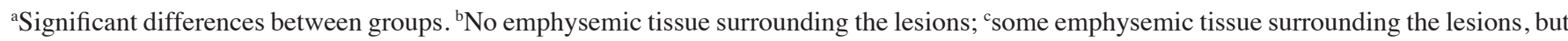
distant from the needle tract; ${ }^{\mathrm{d}}$ prominent emphysemic tissue in the needle tract.

The results of the multivariate logistic regression model showed that the risk of malignant lesions receiving a false-negative diagnosis decreased for every year increase in patient age [odds ratio (OR), 0.97; $\mathrm{P}=0.027$ ] and increased with every millimeter increase in lesion depth $(\mathrm{OR}, 1.03 ; \mathrm{P}=0.008)$ (Table II). The false-negative rates were $6.9 \%$ for a lesion depth of $0 \mathrm{~mm}, 2.56 \%$ for a lesion depth of $1-10 \mathrm{~mm}, 10.8 \%$ for $11-20 \mathrm{~mm}, 11.70 \%$ for $21-30 \mathrm{~mm}$ and $11.67 \%$ for a lesion depth $>30 \mathrm{~mm}$ from the pleural surface. Additional significant risk factors affecting accuracy (false-negative diagnosis) included the presence of hemoptysis (OR, 5.06) and atelectasis (OR, 6.53) (Table II).

False-negative results occurred in 64 malignant cases (8.06\%) (Table I). Among the 64 false-negative cases, a final diagnosis was confirmed by clinical manifestation of disease in 26 cases $(40.6 \%)$, by definitive histology obtained at surgery in 18 cases $(28 \%)$, by a secondary biopsy in 15 cases (23.4\%) and by bronchofibroscope in 3 cases (4.0\%). One case (2\%) was confirmed by the detection of cancer cells in the hydrothorax, and one case was confirmed via thoracoscopy (2\%) (Table III).

Complications of the procedure: Risk factors affecting pneumothorax. The incidence and distribution of pneumothorax, hemorrhage and hemoptysis are presented in Table IV. Among the 1,106 lesions biopsied, 207 (18.71\%) biopsies caused pneumothorax, 251 biopsies were associated with hemorrhage and 58 biopsies were associated with hemoptysis. The risk factors affecting complication rates are presented in Table V.

Table IV shows that lesion location, depth and size, as well as emphysema, atelectasis, position, needle size, number of attempts and hemostasis, had significant effects on the incidence of pneumothorax. The 207 cases of pneumothorax included 192 mild, 11 moderate and 4 severe pneumothoraces that required chest tube drainage.

A higher frequency of pneumothorax was observed in patients with CT evidence of emphysema $(75.54 \%)$ in the needle tract (Table IV). The pneumothorax rate increased with increasing lesion depth. The pneumothorax rate was $4.61,26.15,31.02,33.33$ and $43.94 \%$ for the five groups of lesion depth $(0,1-10,11-20,21-30$ and $>30 \mathrm{~mm}$, respectively) (Fig. 4).

Increasing lesion size $>10 \mathrm{~mm}$ was inversely correlated with the incidence of pneumothorax. In the five groups of lesion size $(\leq 10,11-20,21-30,31-40$ and $>40 \mathrm{~mm})$, the pneumothorax rate was 33.33, 29.58, 21.98, 15.42 and $8.93 \%$, respectively (Table IV).

From multivariate logistic regression analysis, only lesion size and emphysema appeared to significantly affect the incidence of pneumothorax $(\mathrm{P}<0.05$; Table $\mathrm{V})$. The odds of pneumothorax were significantly reduced in subjects with 
Table II. Univariate and multivariate analysis of risk factors affecting accuracy (false-negative rate).

\begin{tabular}{|c|c|c|c|c|}
\hline \multirow[b]{2}{*}{ Risk factor/reference } & \multicolumn{2}{|c|}{ Univariate } & \multicolumn{2}{|c|}{ Multivariate } \\
\hline & OR $(95 \% \mathrm{CI})$ & P-value & OR $(95 \% \mathrm{CI})$ & P-value \\
\hline Gender/female & $1.54(0.83-2.85)$ & 0.167 & & \\
\hline Age, years & $0.97(0.95-0.99)$ & $0.009^{\mathrm{a}}$ & $0.97(0.95-1.00)$ & 0.027 \\
\hline \multicolumn{5}{|c|}{ Lesion location/right upper lobe } \\
\hline Right middle lobe & $0.86(0.19-3.88)$ & 0.844 & & \\
\hline Right lower lobe & $0.72(0.35-1.49)$ & 0.379 & & \\
\hline Left upper lobe & $0.81(0.42-1.57)$ & 0.531 & & \\
\hline Left lower lobe & $0.69(0.32-1.49)$ & 0.344 & & \\
\hline Lesion type/central & $0.34(0.2-0.57)$ & $<0.001^{\mathrm{a}}$ & $0.72(0.37-1.39)$ & 0.321 \\
\hline Lesion depth, mm & $1.03(1.01-1.05)$ & $0.007^{\mathrm{a}}$ & $1.03(1.01-1.05)$ & $0.008^{\mathrm{a}}$ \\
\hline Lesion size, $\mathrm{mm}$ & $1.00(0.99-1.02)$ & 0.894 & & \\
\hline Emphysema/ $/ 0^{\mathrm{b}}$ & $1.06(0.61-1.82)$ & 0.847 & & \\
\hline $1^{\mathrm{c}}$ & $0.65(0.37-1.15)$ & 0.142 & & \\
\hline $2^{\mathrm{d}}$ & $0.68(0.34-1.36)$ & 0.273 & & \\
\hline Contrast enhancement/no & $1.05(0.61-1.81)$ & 0.865 & & \\
\hline Atelectasis/no & $5.75(3.27-10.1)$ & $<0.001^{\mathrm{a}}$ & $6.53(3.12-13.67)$ & $<0.001^{\mathrm{a}}$ \\
\hline \multicolumn{5}{|l|}{ Position/lateral } \\
\hline Prone & $0.87(0.46-1.65)$ & 0.668 & & \\
\hline Supine & $1.04(0.51-2.13)$ & 0.917 & & \\
\hline Needle size/16 G & $2.64(0.81-8.61)$ & 0.107 & & \\
\hline \multicolumn{5}{|l|}{ Number of attempts/ $\leq 2$} \\
\hline 3 & $0.68(0.38-1.21)$ & 0.196 & & \\
\hline$\geq 4$ & $1.76(0.88-3.50)$ & 0.109 & & \\
\hline \multicolumn{5}{|l|}{ Needle-pleura angle $/ \leq 15^{\circ}$} \\
\hline $16-30^{\circ}$ & $0.95(0.4-2.3)$ & 0.916 & & \\
\hline$>30^{\circ}$ & $1.14(0.4-3.32)$ & 0.804 & & \\
\hline Hemostatic/no & $0.89(0.31-2.54)$ & 0.824 & & \\
\hline Pneumothorax/no & $1.52(0.84-2.77)$ & 0.166 & & \\
\hline Hemorrhage/no & $1.29(0.74-2.26)$ & 0.374 & & \\
\hline Hemoptysis/no & $4.64(2.14-10.06)$ & $<0.001^{\mathrm{a}}$ & $5.06(2.19-11.70)$ & $<0.001^{\mathrm{a}}$ \\
\hline
\end{tabular}

${ }^{\mathrm{a}} \mathrm{P}<0.05$. ${ }^{\mathrm{b}}$ No emphysemic tissue surrounding the lesions; ${ }^{\mathrm{c}}$ some emphysemic tissue surrounding the lesions, but distant from the needle tract; dprominent emphysemic tissue in the needle tract. OR, odds ratio; CI, confidence interval.

Table III. Distribution of diagnostic methods used to confirm the false-negative results.

\begin{tabular}{lc}
\hline Confirmation method & $\begin{array}{c}\text { False-negative } \\
\text { rate, n }(\%)\end{array}$ \\
\hline $\begin{array}{l}\text { Clinical manifestations } \\
\text { of disease }\end{array}$ & $26(40.6)$ \\
Surgery & $18(28.0)$ \\
Secondary biopsy & $15(23.4)$ \\
Bronchofibroscope & $3(4.0)$ \\
Thoracoscope & $1(2.0)$ \\
Cancer cell in hydrothorax & $1(2.0)$ \\
Total & $64(100)$ \\
\hline
\end{tabular}

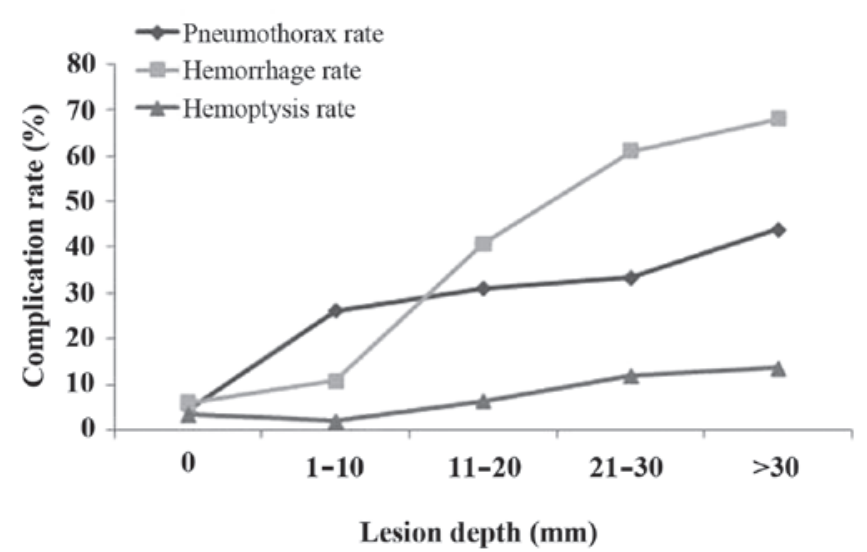

Figure 4. Association between lesion depth and complication rate. 


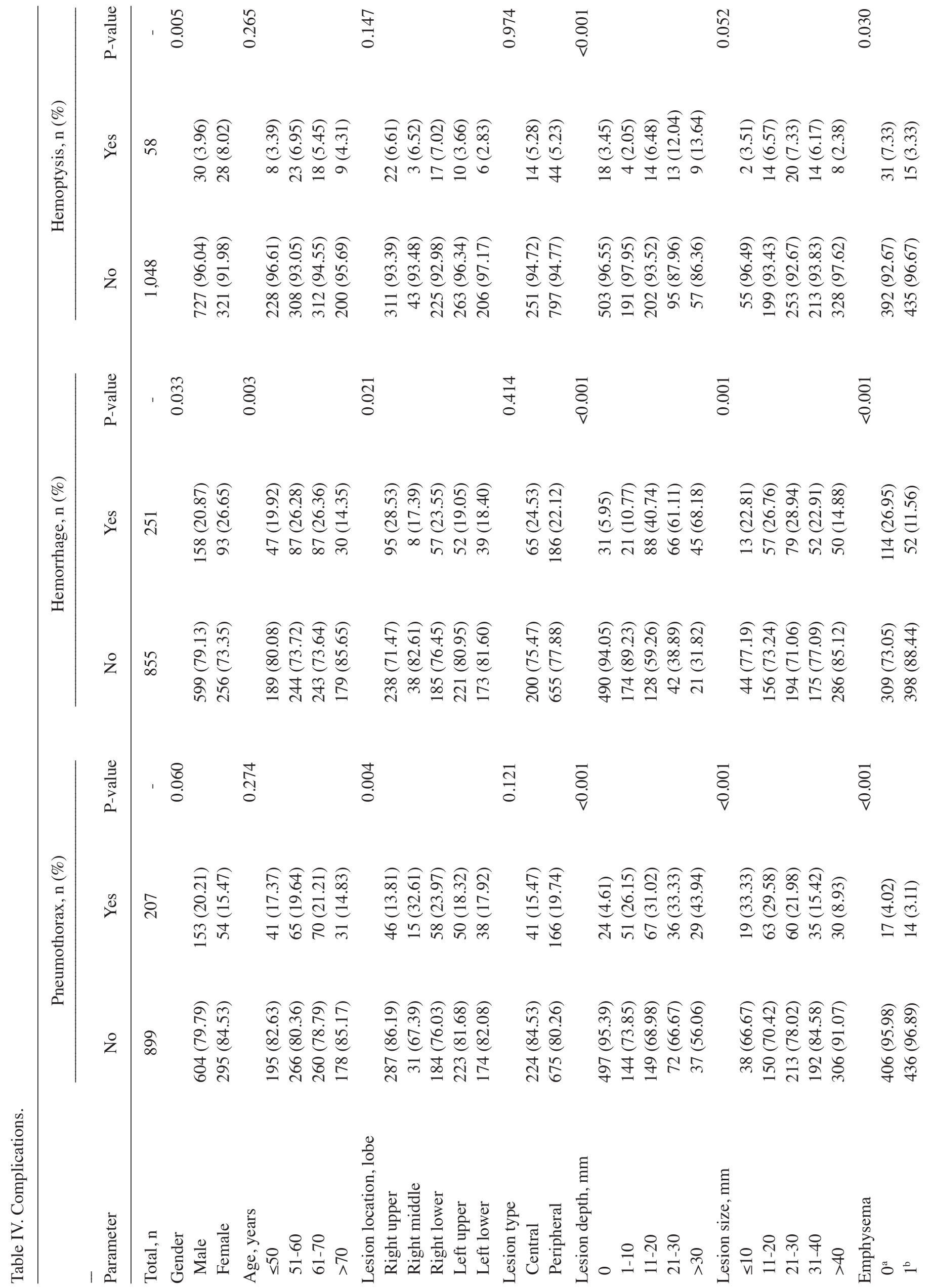




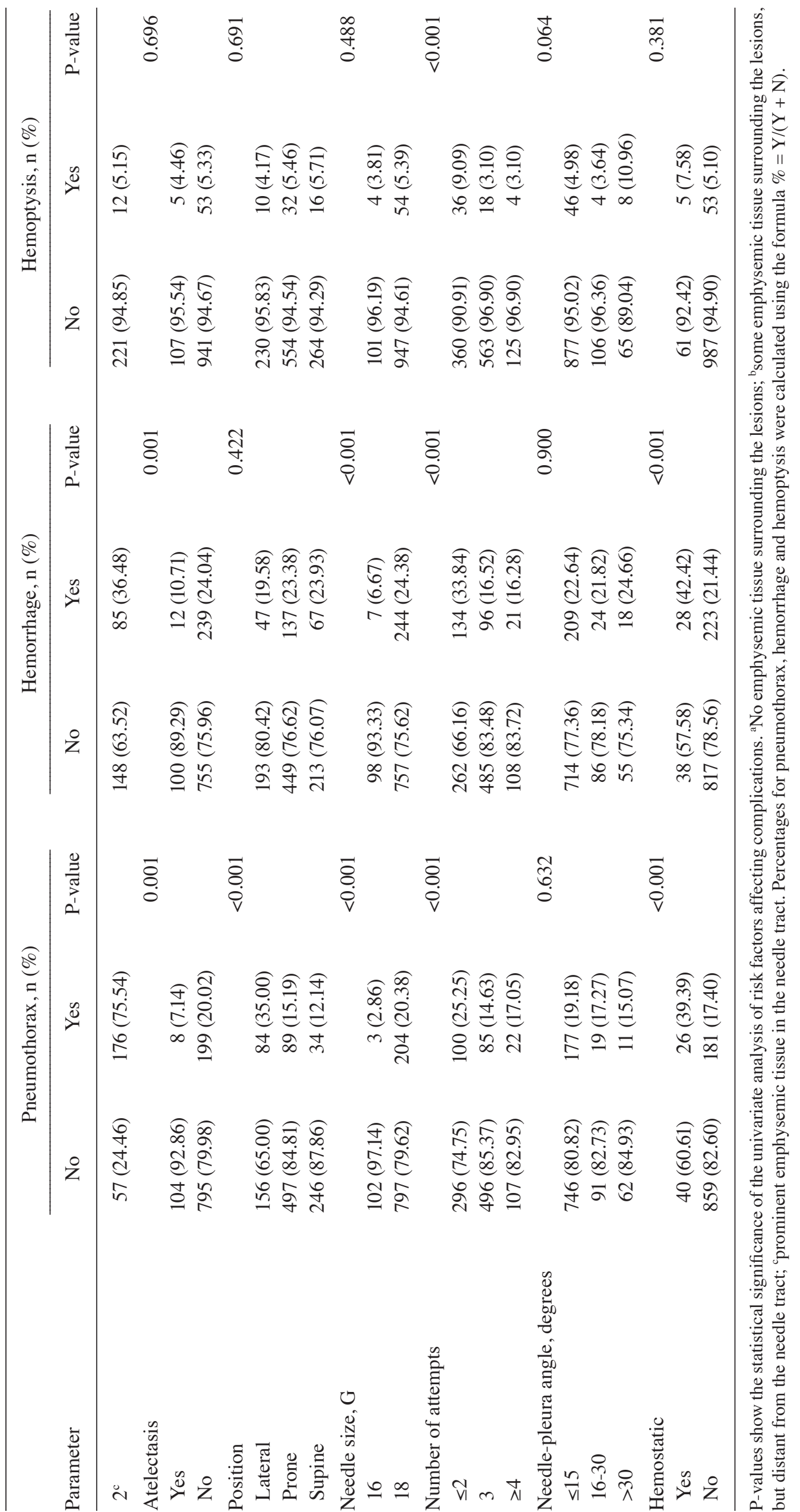


Table V. Statistical analysis of risk factors for complications (pneumothorax, hemorrhage and hemoptysis).

\begin{tabular}{|c|c|c|}
\hline Risk factor/reference & OR $(95 \% \mathrm{CI})$ & P-value \\
\hline \multicolumn{3}{|l|}{ Pneumothorax } \\
\hline \multicolumn{3}{|l|}{ Lesion size/ $\leq 10 \mathrm{~mm}$} \\
\hline $11-20$ & $1.25(0.46-3.37)$ & 0.662 \\
\hline $21-30$ & $0.64(0.23-1.73)$ & 0.377 \\
\hline $31-40$ & $0.48(0.17-1.35)$ & 0.162 \\
\hline$>40$ & $0.32(0.11-0.95)$ & $0.040^{\mathrm{a}}$ \\
\hline \multicolumn{3}{|l|}{ Emphysema $/ 0^{\mathrm{b}}$} \\
\hline $1^{\mathrm{c}}$ & $1.00(0.47-2.12)$ & 0.999 \\
\hline $2^{\mathrm{d}}$ & $72.11(37.35-139.22)$ & $<0.001^{\mathrm{a}}$ \\
\hline \multicolumn{3}{|l|}{ Hemorrhage } \\
\hline \multicolumn{3}{|l|}{ Age/ $\leq 50$ years } \\
\hline $51-60$ & $1.68(1.03-2.75)$ & $0.038^{\mathrm{a}}$ \\
\hline $61-70$ & $1.75(1.05-2.90)$ & $0.031^{\mathrm{a}}$ \\
\hline$>70$ & $0.99(0.53-1.82)$ & 0.961 \\
\hline \multicolumn{3}{|c|}{ Lesion location/right upper lobe } \\
\hline Right middle lobe & $0.39(0.15-1.00)$ & 0.050 \\
\hline Right lower lobe & $0.54(0.33-0.88)$ & $0.014^{\mathrm{a}}$ \\
\hline Left upper lobe & $0.61(0.38-0.99)$ & 0.044 \\
\hline Left lower lobe & $0.48(0.29-0.80)$ & $0.005^{\mathrm{a}}$ \\
\hline \multicolumn{3}{|l|}{ Lesion depth/0 mm } \\
\hline $1-10$ & $1.62(0.88-2.98)$ & 0.122 \\
\hline $11-20$ & $9.56(5.83-15.68)$ & $<0.001^{\mathrm{a}}$ \\
\hline $21-30$ & $24.49(13.36-44.87)$ & $<0.001^{\mathrm{a}}$ \\
\hline$>30$ & $31.51(15.22-65.24)$ & $<0.001^{\mathrm{a}}$ \\
\hline \multicolumn{3}{|l|}{ Emphysema/ $/ 0^{\mathrm{b}}$} \\
\hline $1^{\mathrm{c}}$ & $0.55(0.35-0.87)$ & $0.010^{\mathrm{a}}$ \\
\hline $2^{\mathrm{d}}$ & $0.51(0.33-0.80)$ & $0.004^{\mathrm{a}}$ \\
\hline \multicolumn{3}{|l|}{ Hemoptysis } \\
\hline Gender/female & $0.55(0.31-0.96)$ & $0.036^{\mathrm{a}}$ \\
\hline \multicolumn{3}{|l|}{ Lesion depth/0 mm } \\
\hline $1-10$ & $0.50(0.16-1.53)$ & 0.226 \\
\hline $11-20$ & $1.70(0.79-3.66)$ & 0.174 \\
\hline $21-30$ & $3.10(1.35-7.12)$ & $0.008^{\mathrm{a}}$ \\
\hline$>30$ & $3.85(1.49-10.00)$ & $0.006^{\mathrm{a}}$ \\
\hline \multicolumn{3}{|l|}{ Number of attempts/ $\leq 2$} \\
\hline 3 & $0.40(0.21-0.73)$ & $0.003^{\mathrm{a}}$ \\
\hline$\geq 4$ & $0.42(0.14-1.25)$ & 0.118 \\
\hline
\end{tabular}

${ }^{\mathrm{a}} \mathrm{P}<0.05 .{ }^{\mathrm{b}}$ No emphysemic tissue surrounding the lesions; ${ }^{\mathrm{c}}$ Some emphysemic tissue surrounding the lesions, but distant from the needle tract; dprominent emphysemic tissue in the needle tract. OR, odds ratio; CI, confidence interval.

a lesion size of $>40 \mathrm{~mm}(\mathrm{OR}, 0.32 ; \mathrm{P}=0.04)$ compared with those in subjects with a lesion size of $<10 \mathrm{~mm}$ and were significantly higher in subjects with prominent emphysemic tissue in the needle tract $(\mathrm{OR}, 72.11 ; \mathrm{P}<0.001)$ (Table V) compared with those in subjects with no emphysemic tissue surrounding the lesions. As shown in Fig. 4, the pneumothorax rates increased with increasing lesion depth $(\mathrm{P}<0.001)$, as did the rates of hemorrhage and hemoptysis $(\mathrm{P}<0.001)$.
Complications of the procedure: Risk factors affecting hemorrhage. A total of 251 biopsies (22.7\%) caused perifocal and needle track hemorrhages, including 193 mild, 50 moderate and 8 severe, of which 52 were hemopneumothoraces. Gender, age, emphysema, atelectasis, needle size, number of attempts and hemostasis, as well as lesion location, depth and size, appeared to have a significant effect on the incidence of hemorrhage (Table IV). Lesions 
Table VI. Number of biopsy attempts required for each lesion depth range.

\begin{tabular}{lrccr}
\hline & \multicolumn{3}{c}{ Number of biopsy attempts, $\mathrm{n}(\%)$} \\
\cline { 2 - 4 } Lesion depth, mm & \multicolumn{1}{c}{$\leq 2$} & 3 & \multicolumn{1}{c}{ P-value } \\
\hline 0 & $9(50.00)$ & $9(50.00)$ & $0(0.00)$ & 0.003 \\
$1-10$ & $2(50.00)$ & $2(50.00)$ & $0(0.00)$ & $4(28.57)$ \\
$11-20$ & $5(35.71)$ & $5(35.71)$ & $0(0.00)$ & \\
$21-30$ & $12(92.31)$ & $1(7.69)$ & $0(0.00)$ & \\
$>30$ & $8(88.89)$ & $1(11.11)$ &
\end{tabular}

$>10 \mathrm{~mm}$ in depth were associated with an increased incidence of hemorrhage (Table IV). Lesions in the right upper lobe were more prone to hemorrhage compared with those in other locations $(28.53 \%$, Table IV). The hemorrhage rate in the group that had emphysemic tissue in the needle tract $(36.48 \%)$ was markedly increased compared with the bleeding rate from the needle pathway without emphysema $(26.95 \%)$ (Table IV). Based on multivariate logistic regression analysis, age, lesion location and depth and emphysema all had a significant effect on the incidence of hemorrhage $(\mathrm{P}<0.05)$. The odds of hemorrhage were significantly higher in patients in the 61-70-year-old group ( $\mathrm{OR}, 1.75 ; \mathrm{P}=0.031)$ compared with those in patients aged $\leq 50$ years and were significantly lower in those with lesions located in lobes other than the right upper lobe (all $\mathrm{P}<0.05)$. The odds of hemorrhage were significantly higher in subjects with lesion depths of 11-20, 21-30 and $>30 \mathrm{~mm}$ (ORs of 9.56, 24.49 and 31.51 , respectively; $\mathrm{P}<0.001)$ compared with those in subjects with a lesion depth of $0 \mathrm{~mm}$. Multivariate analysis, following adjustment for confounding factors, showed that the odds of hemorrhage were significantly reduced in lesions with some or prominent emphysemic tissue compared with those in lesions without surrounding emphysemic tissue (ORs of 0.55 and 0.51 , respectively; $\mathrm{P}=0.010$ and 0.004 , respectively; Table V).

Complications of the procedure: Risk factors affecting hemoptysis. The hemoptysis rate was 5.2\% (Table IV). Gender, lesion depth, emphysema and number of attempts appeared to have a significant effect on the incidence of hemoptysis (Table IV). Based on multivariate logistic regression analysis, gender, lesion depth and number of biopsy attempts had a significant effect on the incidence of hemoptysis $(\mathrm{P}<0.05)$. The odds of hemoptysis were significantly lower in males compared with those in females (OR, 0.55; $\mathrm{P}=0.036$ ); were significantly higher in subjects with lesion depths of 21-30 and $>30 \mathrm{~mm}$ compared with those in patients with a lesion depth of $0 \mathrm{~mm}$ (ORs of 3.1 and 3.85, respectively; $\mathrm{P}=0.008$ and 0.006 , respectively); and were significantly lower in subjects with 3 biopsy attempts compared with those in subjects with $\leq 2$ attempts (OR, 0.4; $\mathrm{P}=0.003$; Table $\mathrm{V})$.

Total ED and needle dwell time. The total mean ED was $0.54 \pm 0.14 \mathrm{mSv}$ (range, 0.21-0.95 $\mathrm{mSv}$ ). The mean duration of the procedure was $16 \pm 2 \mathrm{~min}$ and the mean time spent by the needle in the parenchyma (mean needle dwell time) was
$5 \pm 3 \mathrm{sec}$ (range, $3-8 \mathrm{sec}$ ) per biopsy. A total of 396 patients (35.8\%) each received 2 biopsy attempts and 581 patients $(52.53 \%)$ each received 3 attempts (Table I).

\section{Discussion}

Low-dose, CT-guided ACNB of pulmonary lesions with EPL has high diagnostic accuracy and improved safety compared with conventional CT-guided biopsy. The sensitivity, specificity, positive predictive value and negative predictive value of the EPL method were 91.9, 100, 100 and 82.9\%, respectively, and showed improvements compared with the values obtained in previous studies $(13,18-24)$. The overall diagnostic accuracy of EPL in the present study was $94.2 \%$. Results of multivariate analysis demonstrated that significant risk factors affecting accuracy included younger age, atelectasis, hemoptysis and lesion depth (all $\mathrm{P}<0.03$ ). Younger age $(\leq 50$ years old) has not been investigated in previously published studies as a risk factor affecting accuracy and is, therefore, a novel finding. Among the 1,106 lesions biopsied, 207 resulted in pneumothorax, 251 in hemorrhage and 58 in hemoptysis. Lesion size and emphysema were demonstrated to exert a significant influence on the incidence of pneumothorax. Age, lesion location and depth and emphysema significantly affected the incidence of hemorrhage. In addition, gender, lesion depth and number of attempts had a significant effect on the incidence of hemoptysis.

With regard to the risk factors affecting accuracy, the results of multivariate analysis showed that significant risk factors affecting accuracy included younger age, atelectasis, hemoptysis and lesion depth (all $\mathrm{P}<0.03)$. Younger age $(\leq 50$ years old) has not previously been reported in the literature as a risk factor affecting accuracy and is, therefore, a novel finding. To the best of our knowledge, this is the first study to show a correlation between younger age and diagnostic accuracy. Other studies have investigated the effect of age on accuracy using various lung biopsy techniques $(26,32,33)$. All three of these studies, however, failed to find any correlation between accuracy and age $(26,32,33)$. The reason for the discrepancy between previously published results and the present findings may be associated with the high false-negative rate in the younger patients in the malignant group. This high false-negative rate may have been due to the increased inflammation and necrosis in the tumors of younger patients, which increased the difficulty of confirming a malignant diagnosis. Among the 15 false-negative cases in the malignant group of patients aged $\leq 50$ years, 4 cases exhibited obvious necrosis 
and 3 cases exhibited a combination of inflammation and necrosis. The final diagnoses included 8 cases of lung cancer, 5 cases of metastatic tumor, one malignant lesion and one case of malignant fibrous histiocytoma (data not shown).

The effect of atelectasis on accuracy may have been due to difficulty in distinguishing lesions from atelectasis, as the majority of lesions complicated with atelectasis were of a central type and exhibited necrosis. In addition, enhancement on CT scan appeared to exert no effect on diagnostic accuracy in the present study. The effect of hemoptysis on accuracy may have been due to the fact that the procedure was terminated due to the risk of air embolism if the patients developed serious cough or hemoptysis (25). Finally, it appeared that diagnostic accuracy decreased in proportion to increasing lesion depth $>10 \mathrm{~mm}$; this finding was expected, as deeper lesions are more difficult to biopsy.

The EPL method exhibits an acceptable complication rate. Among the 1,106 lesions biopsied, 207 biopsies (18.71\%) led to pneumothorax. The EPL method appears to reduce damage to the visceral pleura, which may partly explain the reduced pneumothorax rate in the present study compared with rates reported using other techniques (13-15,19-21). Furthermore, the pneumothorax rate was relatively low despite multiple needle passes, which may have been due to the breath-hold training undergone by the patients at the beginning of the procedure.

As reported in previous studies, deeper lesions were associated with a higher rate of pneumothorax $(10,14,34)$. The pneumothorax rates in the present study increased with increasing lesion depth $(\mathrm{P}<0.001)$. Furthermore, the pneumothorax rate in the present study was elevated in patients with emphysemic tissue surrounding the lesions, which increased the possibility of pulmonary vascular tearing, while it remained relatively low in the group without emphysema, younger patients or lesions situated in superficial parts.

For conventional CT-guided ACNB, the incidence of pulmonary hemorrhage reported in the literature varies between 4 and $42 \%$, and the hemoptysis rate varies between 2 and $25 \%(13,14,18,19,22,24,28)$. In the present study, 251 biopsies $(22.69 \%)$ were associated with hemorrhage and 58 biopsies $(5.24 \%)$ were associated with hemoptysis (Table IV). Few reports have described an association between lesion location and hemorrhage $(35,36)$. Analysis of the present data showed that right upper lobe lesions had a higher rate of hemorrhage; however, this finding may have been due to random error. Furthermore, the rates of hemorrhage and hemoptysis increased significantly with increasing lesion depth $(\mathrm{P}<0.001)$. The risk of hemorrhage was significantly lower in lesions with some or prominent emphysemic tissue compared with that in lesions with no surrounding emphysemic tissue (OR, 0.55 and 0.51 , respectively; Table V). The risk of hemoptysis was also significantly lower in subjects with 3 biopsy attempts compared with that in patients that underwent $\leq 2$ attempts, which may have been due to the fact that fewer deep-lesion biopsy attempts were made than superficial-lesion biopsy attempts (Table VI). Biopsy duration can increase if the surgeon consideres more tissue biopsy specimens are required, which can result in a relatively high rate of bleeding. In addition, the administration of hemostatic drugs can reduce the rate of hemoptysis.
The present study contained several limitations, including its retrospective nature and the fact that the study was conducted at a single hospital and included primarily inpatients. In addition, hemocoagulase was used in patients with a high risk of bleeding prior to surgery, as it has been demonstrated to reduce bleeding from our clinical observations, particularly the incidence of hemoptysis. The injection of hemocoagulase was not randomized or controlled and was used only in certain cases. Thus, the inconsistent application of hemocoagulase may have affected the assessment of hemorrhage and hemoptysis (i.e., without the benefit of a randomized control, it may have affected the statistical results). As this study was retrospective, this limitation could not be altered.

In conclusion, the present EPL method for performing CT-guided ACNB is a novel technique that has been described in one previous study in the literature (24). This EPL method has been demonstrated to be a safe, fast and accurate diagnostic method with reduced dwell time compared with conventional techniques. The EPL method maintains the needle tip outside the visceral pleural prior to biopsy. Consequently, the time spent by the needle within the parenchyma (dwell time) is significantly decreased compared with that associated with conventional methods $(2,19,22,27)$. In addition, the entire procedure, on average, has a duration of $16 \pm 2 \mathrm{~min}$, and requires a lower dose of radiation compared with those employed in previous studies $(37,38)$. The results of the multivariate analysis indicated that significant risk factors affecting accuracy included younger age, atelectasis, hemoptysis and lesion depth $(\mathrm{P}<0.03)$. To the best of our knowledge, younger age ( $\leq 50$ years old) has not been previously reported in the literature as a risk factor affecting accuracy and is therefore a novel observation.

\section{Acknowledgements}

The present study was supported by the Key Foundation of Hubei Natural Science Funds (no. 2012FFB04414).

\section{References}

1. Wallace MJ, Krishnamurthy S, Broemeling LD, Gupta S, Ahrar K, Morello FA Jr and Hicks ME: CT-guided percutaneous fine-needle aspiration biopsy of small $(\leq 1 \mathrm{~cm})$ pulmonary lesions. Radiology 225: 823-828, 2002.

2. Laurent F, Latrabe V, Vergier B, Montaudon M, Vernejoux JM and Dubrez J: CT-guided transthoracic needle biopsy of pulmonary nodules smaller than $20 \mathrm{~mm}$ : Results with an automated 20 -gauge coaxial cutting needle. Clin Radiol 55: 281-287, 2000.

3. Guimaraes MD, de Andrade MQ, da Fonte AC, Chojniak R and Gross JL: CT-guided cutting needle biopsy of lung lesions - an effective procedure for adequate material and specific diagnose. Eur J Radiol 80: e488-e490, 2011.

4. Wu RH, Tzeng WS, Lee WJ, Chang SC, Chen CH, Fung JL, Wang YJ and Mak CW: CT-guided transthoracic cutting needle biopsy of intrathoracic lesions, comparison between coaxial and single needle technique. Eur J Radiol 81: e712-e716, 2012.

5. Hiraki T, Mimura H, Gobara H, Iguchi T, Fujiwara H, Sakurai J, Matsui Y, Inoue D, Toyooka S, Sano Y and Kanazawa S: CT fluoroscopy-guided biopsy of 1,000 pulmonary lesions performed with 20-gauge coaxial cutting needles: Diagnostic yield and risk factors for diagnostic failure. Chest 136: 1612-1617, 2009.

6. Geraghty PR, Kee ST, McFarlane G, Razavi MK, Sze DY and Dake MD: CT-guided transthoracic needle aspiration biopsy of pulmonary nodules: Needle size and pneumothorax rate. Radiology 229: 475-481, 2003. 
7. Gupta S, Krishnamurthy S, Broemeling LD, Morello FA Jr, Wallace MJ, Ahrar K, Madoff DC, Murthy R and Hicks ME: Small $(</=2-\mathrm{cm})$ subpleural pulmonary lesions: Short-versus long-needle-path CT-guided Biopsy - comparison of diagnostic yields and complications. Radiology 234: 631-637, 2005.

8. Haramati LB and Aviram G: What constitutes effective management of pneumothorax after CT-guided needle biopsy of the lung? Chest 121: 1013-1015, 2002.

9. Klein JS, Salomon G and Stewart EA: Transthoracic needle biopsy with a coaxially placed 20 -gauge automated cutting needle: Results in 122 patients. Radiology 198: 715-720, 1996.

10. Saji H, Nakamura H, Tsuchida T, Tsoboi M, Kawate N, Konaka C and Kato $\mathrm{H}$ : The incidence and the risk of pneumothorax and chest tube placement after percutaneous CT-guided lung biopsy: The angle of the needle trajectory is a novel predictor. Chest 121: $1521-1526,2002$

11. Beşir FH, Altin R, Kart L, Akkoyunlu M, Ozdemir H, Ornek T and Gündoğdu S: The results of computed tomography guided tru-cut transthoracic biopsy: Complications and related risk factors. Wien Klin Wochenschr 123: 79-82, 2011.

12. Khan MF, Straub R, Moghaddam SR, Maataoui A, Gurung J, Wagner TO, Ackermann H, Thalhammer A, Vogl TJ and Jacobi V: Variables affecting the risk of pneumothorax and intrapulmonal hemorrhage in CT-guided transthoracic biopsy. Eur Radiol 18: 1356-1363, 2008.

13. Yeow KM, Su IH, Pan KT, Tsay PK, Lui KW, Cheung YC and Chou AS: Risk factors of pneumothorax and bleeding: Multivariate analysis of 660 CT-guided coaxial cutting needle lung biopsies. Chest 126: 748-754, 2004.

14. Ko JP, Shepard JO, Drucker EA, Aquino SL, Sharma A, Sabloff B, Halpern E and McLoud TC: Factors influencing pneumothorax rate at lung biopsy: Are dwell time and angle of pleural puncture contributing factors? Radiology 218: 491-496, 2001.

15. Yildirim E, Kirbas I, Harman A, Ozyer U, Tore HG, Aytekin C and Boyvat F: CT-guided cutting needle lung biopsy using modified coaxial technique: factors effecting risk of complications. Eur J Radiol 70: 57-60, 2009.

16. Charig MJ and Phillips AJ: CT-guided cutting needle biopsy of lung lesions-safety and efficacy of an out-patient service. Clin Radiol 55: 964-969, 2000.

17. Topal U and Berkman YM: Effect of needle tract bleeding on occurrence of pneumothorax after transthoracic needle biopsy. Eur J Radiol 53: 495-499, 2005.

18. Yamaura H, Inaba Y, Arai Y, Matsueda $\mathrm{K}$ and Hatooka S: Massive intrathoracic haemorrhage after CT-guided lung biopsy. Br J Radiol 73: 1105-1107, 2000.

19. Laurent F, Michel P, Latrabe V, Tunon de Lara M and Marthan R: Pneumothoraces and chest tube placement after CT-guided transthoracic lung biopsy using a coaxial technique: Incidence and risk factors. AJR Am J Roentgenol 172: 1049-1053, 1999.

20. Topal U and Ediz B: Transthoracic needle biopsy: Factors effecting risk of pneumothorax. Eur J Radiol 48: 263-267, 2003.

21. Chakrabarti B, Earis JE, Pandey R, Jones Y, Slaven K, Amin S, McCann C, Jones PL, Thwaite E, Curtis JM and Warburton CJ: Risk assessment of pneumothorax and pulmonary haemorrhage complicating percutaneous co-axial cutting needle lung biopsy. Respir Med 103: 449-455, 2009.

22. Tsukada H, Satou T, Iwashima A and Souma T: Diagnostic accuracy of CT-guided automated needle biopsy of lung nodules. AJR Am J Roentgenol 175: 239-243, 2000.
23. Wei YH, Liao MY and Xu LY: Diagnostic value of CT-guided extrapleural locating transthoracic automated cutting needle biopsy of lung lesions. Zhong Hua Zhong Liu Za Zhi 33: 473-475, 2011 (In Chinese).

24. Liao MY, Zhou YF, Tian ZX, Luo R, Qu YJ and Xu LY: The factor analysis of the incidence of complication in CT-guided lung automated cutting needle biopsy with extrapleural locating method. Zhong Hua Yi Xue Za Zhi 90: 1747-1751, 2010 (In Chinese).

25. Burbank F, Kaye K, Belville J, Ekuan J and Blumenfeld M: Image-guided automated core biopsies of the breast, chest, abdomen and pelvis. Radiology 191: 165-171, 1994.

26. Montaudon M, Latrabe V, Pariente A, Corneloup O, Begueret $\mathrm{H}$ and Laurent F: Factors influencing accuracy of CT-guided percutaneous biopsies of pulmonary lesions. Eur Radiol 14: 1234-1240, 2004

27. Funk C, Gmür J, Herold R and Straub PW: Reptilase-R - a new reagent in blood coagulation. Br J Haematol 21: 43-52, 1971.

28. Kinoshita F, Kato T, Sugiura K, Nishimura M, Kinoshita T, Hashimoto M, Kaminoh T and Ogawa T: CT-guided transthoracic needle biopsy using a puncture site-down positioning technique. AJR Am J Roentgenol 187: 926-932, 2006.

29. Dennie CJ, Matzinger FR, Marriner JR and Maziak DE: Transthoracic needle biopsy of the lung: Results of early discharge in 506 outpatients. Radiology 219: 247-251, 2001.

30. Watanuki Y, Suzuki S, Nishikawa M, Miyashita A and Okubo T: Correlation of quantitative $\mathrm{CT}$ with selective alveolobronchogram and pulmonary function tests in emphysema. Chest 106: 806-813, 1994.

31. McCullough C, Cody D, Edyvean S, Geise R, Gould B, Keat N, Huda W, Judy P, Kalender W, McNitt-Gray M, et al: The measurement, reporting, and management of radiation dose in CT. Report of the AAPM Task Group 23 of the Diagnostic Imaging Council CT Committee. American Association of Physicists in Medicine, College Park, MD, USA, pp.1-28, 2008.

32. Choi JW, Park CM, Goo JM, Park YK, Sung W, Lee HJ, Lee SM, Ko JY and Shim MS: C-arm cone-beam CT-guided percutaneous transthoracic needle biopsy of small $(\leq 20 \mathrm{~mm})$ lung nodules: Diagnostic accuracy and complications in 161 patients. AJR Am J Roentgenol 199: W322-W330, 2012.

33. Heyer CM, Reichelt S, Peters SA, Walther JW, Müller KM and Nicolas V: Computed tomography-navigated transthoracic core biopsy of pulmonary lesions: Which factors affect diagnostic yield and complication rates? Acad Radiol 15: 1017-1026, 2008.

34. Yeow KM, See LC, Lui KW, Lin MC, Tsao TC, Ng KF and Liu HP: Risk factors for pneumothorax and bleeding after CT-guided percutaneous coaxial cutting needle biopsy of lung lesions. J Vasc Interv Radiol 12: 1305-1312, 2001.

35. Nour-Eldin NE, Alsubhi M, Naguib NN, Lehnert T, Emam A, Beeres M, Bodelle B, Koitka K, Vogl TJ and Jacobi V: Risk factor analysis of pulmonary hemorrhage complicating CT-guided lung biopsy in coaxial and non-coaxial core biopsy techniques in 650 patients. Eur J Radiol 83: 1945-1952, 2014

36. Rizzo S, Preda L, Raimondi S, Meroni S, Belmonte M, Monfardini L, Veronesi G and Bellomi M: Risk factors for complications of CT-guided lung biopsies. Radiol Med 116: 548-563, 2011 (In English and Italian).

37. Smith JC, Jin DH, Watkins GE, Miller TR, Karst JG and Oyoyo UE: Ultra-low-dose protocol for CT-guided lung biopsies. J Vasc Interv Radiol 22: 431-436, 2011.

38. Heyer CM, Lemburg SP, Kagel T, Mueller KM, Nuesslein TG, Rieger $\mathrm{CH}$ and Nicolas V: Evaluation of chronic infectious interstitial pulmonary disease in children by low-dose CT-guided transthoracic lung biopsy. Eur Radiol 15: 1289-1295, 2005. 